NGL $-05-002-105$

\title{
Shock-Induced Volatile Loss from a Carbonaceous Chondrite: Implications for Planetary Accretion
}

\author{
James A. Tyburczy*, Benjamin Frisch, and Thomas J. Ahrens \\ Seismological Laboratory 252-21 \\ California Institute of Technology \\ Pasadena, CA 91125
}

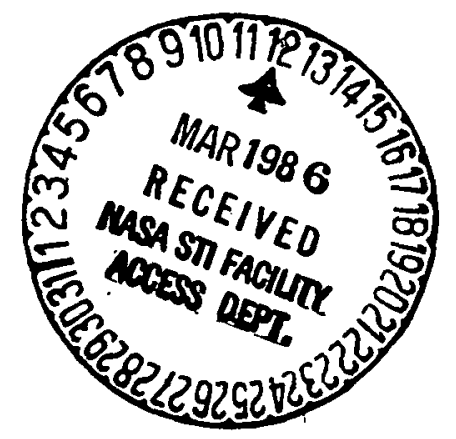

Solid recovery impact-induced volatile loss experiments on the Murchison C2M meteorite indicate that for an impact of a given velocity, $\mathrm{H}_{2} \mathrm{O}$ and total volatiles are driven from the sample in the same proportion as present initially. Thus, the primitive surface volatile budget (volatiles reacted with the solid surface plus atmosphere) of a planet growing by accretion would have the same bulk elemental composition as the volatiles in the incident planetesimals. Incipient devolatilization of Murchison occurs at an initial shock pressure of about $11 \mathrm{GPa}$ and complete devolatilization occurs at a pressure of about $30 \mathrm{GPa}$. For the Earth, incipient and complete devolatilization of accreting planetesimals would occur when the planet reached approximately $12 \%$ and $27 \%$, respectively, of its present-day radius. Thus, impact-induced devolatilization would profoundly affect the volatile distribution within the accreting planet. Prior to metallic core formation and internal differentiation the growing planet would have a very small core with the same volatile content as the incident material, a volatile depleted 'mantle', and an extremely volatile rich surface. In the case of the Earth, $99.4 \mathrm{wt} \%$ of the total incident volatile material would end up on or near the planetary surface.

*now at Department of Geology, Arizona State University, Tempe, AZ 85287 


\section{Introduction}

Impact-induced volatile release during planetary accretion may have played an important role in planetary development and in atmospheric and oceanic formation $\{1,2$, $3,4]$. Previous experimental results indicate that the minerals serpentine and calcite begin to devolatilize (i.e., lose $\mathrm{H}_{2} \mathrm{O}$ and $\mathrm{CO}_{2}$, respectively) upon impact at initial shock pressures of 10 to $15 \mathrm{GPa}$ and completely devolatilize at shock pressures of 30 to $40 \mathrm{GPa}$ $[5,6,7]$. Assuming homogeneous accretion and symmetric impact, infalling planetesimals could have achieved impact velocities sufficient to generate shock pressures of these magnitudes when the Earth's radius was about 10 to $15 \%$ and 25 to $35 \%$, respectively, of its present value. Thus, extrapolation from single-mineral results suggests that impact-induced devolatilization would have been a major feature of planetary accretion throughout most of the growth period of an Earth-sized planet.

We report here results of shock recovery experiments on Murchison carbonaceous chondrite (C2M) performed to determine the conditions for loss of $\mathrm{H}_{2} \mathrm{O}$ and other volatiles upon impact from material more representative of an accreting planetesimal than single minerals. One reasonable form in which the volatiles of the terrestrial planets may have arrived is in a mineral assemblage similar to that found in carbonaceous chondrites. It is important to study this material directly because shock propagation, and hence shock-induced devolatilization, in a heterogeneous medium is complicated by local variations in mechanical properties that can lead to localized heating, chemical reaction, and other types of anomalous behavior. Furthermore, the phyllosilicates that comprise the bulk of the matrix of Murchison include a significant proportion of Fe-rich material [8], whereas the serpentine shock recovery work performed to date is confined to the $\mathrm{Mg}$ end

members antigorite and lizardite $[5,7,9]$. Volatile-containing minerals present in Murchison are listed in Table 1. 


\section{Experimental}

The experimental procedure used was similar to that employed in previous solid recovery shock-induced devolatilization studies [5]. Murchison samples (discs $4.4 \mathrm{~mm}$ in diameter, $0.5 \mathrm{~mm}$ thick) were polished until the surfaces were flat and held in vented target assemblies that exposed the samples to the ambient atmosphere during the impact. The assemblies and flyer plates were made of stainless steel, type 304. The experiments were performed on the $20 \mathrm{~mm}$ propellant gun at the California Institute of Technology. Sample shock pressure was calculated using a one-dimensional impedance match method [10]. The Murchison Hugoniot was assumed to be the same as that determined by R. G. McQueen for a 'serpentine' of similar density (see [11]). The shock wave equation of state parameters used for Murchison were $\rho_{\mathrm{o}}=2.85 \mathrm{~g} / \mathrm{cm}^{3}, \mathrm{C}_{\mathrm{o}}=5.80 \mathrm{~km} / \mathrm{s}$, and $\mathrm{S}=0.62$ (where $\mathrm{U}_{\mathrm{s}}=\mathrm{C}_{\mathrm{o}}+\mathrm{S} \mathrm{u}_{\mathrm{p}}, \mathrm{U}_{\mathrm{s}}$ is the shock velocity, and $\mathrm{u}_{\mathrm{p}}$ is the particle velocity) and were obtained from a linear fit to McQueen's $U_{s}-u_{p}$ data in the range 0 $\leq \mathrm{u}_{\mathrm{p}} \leq 3 \mathrm{~km} / \mathrm{s}[11]$

In the recovery assembly, the sample is sandwiched between two steel surfaces. During the shock event the sample is shocked first to a pressure-density point on the sample Hugoniot, but subsequent reverberations bring the sample to a higher pressure state with a density greater than that of the Hugoniot (see [12], for a description of reverberations in shock recovery experiments). In this work we report both the initial (Hugoniot) shock pressure $P_{i}$, and the peak reverberated pressure $P_{p}$ for each shot. In applying the results to models of planetary accretion, we use a formulation for devolatilization as a function of $P_{i}$ (as opposed to $P_{p}$ ). This is because current theoretical models of the impact-induced devolatilization process are generally based on shock entropy calculations $[3,13,14]$, and because after the initial shock, the reverberations are nearly isentropic. Thus, the entire entropy increase of a sample during a shock recovery experiment occurs during the first shock. Previous shock recovery experiments have often been reported in terms of $P_{p}[6,15,16]$. Data used from previous studies have been 
corrected to indicate $\mathrm{P}_{\mathrm{i}}$ (see discussion).

After the shock experiment, the impacted sample was recovered from the target assembly and analyzed for $\mathrm{H}_{2} \mathrm{O}$ and total volatile content. Shock-induced $\mathrm{H}_{2} \mathrm{O}$ and volatile loss were obtained by comparison with analyses of unshocked material. Total volatile content was measured by thermogravimetric analysis (TGA) using a Mettler Thermoanalyzer $2000 \mathrm{C}$. A heating rate of $5^{\circ} \mathrm{C} / \mathrm{min}$, a maximum temperature of $1200^{\circ} \mathrm{C}$, and a nitrogen flow rate of $20 \mathrm{ml} / \mathrm{min}$ were employed. The total volatile content of unshocked Murchison released over the range $200^{\circ} \mathrm{C}-1200^{\circ} \mathrm{C}$ was $10.09 \pm 0.17$ wt \%. Water content was determined using a DuPont Moisture Evolution Analyzer with a maximum temperature of $1000^{\circ}$ using $\mathrm{N}_{2}$ as a carrier gas. The Moisture Analyzer was operated manually; the temperature was increased in increments of $50-100^{\circ} \mathrm{C}$, whenever the cell voltage indicated that the electrolytic cell was below the saturation level. This procedure was adopted to allow minimum analysis time, thereby minimizing the baseline correction and yielding the most precise total $\mathrm{H}_{2} \mathrm{O}$ values. $\mathrm{H}_{2} \mathrm{O}$ loss as a function of temperature under constant heating rate conditions were not obtained as a result of using this procedure. The $\mathrm{H}_{2} \mathrm{O}$ content of unshocked Murchison used for reference in this work was $6.50 \pm 0.20 \mathrm{wt} \%\left(200-1000^{\circ} \mathrm{C}\right)$.

\section{Results and Discussion}

Figure 1 shows representative TGA curves for shocked and unshocked Murchison. Unshocked Murchison meteorite loses mass over a broad temperature range, about $260^{\circ} \mathrm{C}-1020^{\circ} \mathrm{C}$, and the minor structure in the curve indicates that different components are decomposing in different temperature intervals. The TGA curves of the shocked material display much less structure. Mass loss begins at a higher temperature than for the unshocked material, $650-750^{\circ} \mathrm{C}$, indicating that the more labile materials were decomposed during shock and release. No attempt was made to determine which components of the matrix were decomposed during the shock. 
Total volatile loss and $\mathrm{H}_{2} \mathrm{O}$ loss results are listed in Table 2. These data are plotted in Figure 2. Incipient devolatilization occurs at an initial shock pressure $P_{i}$ of about $11 \mathrm{GPa}$, and complete devolatilization occurs at an initial shock pressure of about 30 GPa. Aside from one apparently erroneous data point, there is no discernible difference between $\mathrm{H}_{2} \mathrm{O}$ loss and total volatile loss as a function of initial shock pressure. Therefore, there is no fractionation of $\mathrm{H}_{2} \mathrm{O}$ relative to total volatiles caused by impact-induced devolatilization of carbonaceous chondritic material. The atmospheric (or surficial) complement of volatiles in an atmosphere created by impact induced degassing of planetesimals will have the same bulk elemental composition as the volatiles contained in the incident material, and will also be the same as that of the buried volatile component. Chemical reaction, both in the gas phase and with surficial materials, will change the actual speciation.

It must be stressed that the above conclusion applies strictly only to those volatiles released in an analysis carried out in a $\mathrm{N}_{2}$ carrier gas, at temperatures up to $1200^{\circ} \mathrm{C}$. Analysis under oxidizing or reducing conditions would liberate a different complement of volatiles. For example, graphite is stable (non-volatile) at $1200^{\circ} \mathrm{C}$ in $\mathrm{N}_{2}$, but would be oxidized to $\mathrm{CO}_{2}$ (i.e., considered a volatile) in an oxidizing atmosphere. Furthermore, there are strong indications that the degree of impact-induced devolatilization depends on the ambient atmospheric conditions during both the shock experiments $[7,14,17]$ and planetary accretion. In the experiments described here, the sample was exposed to air during the shock. Details of these atmospheric dependences are subjects for further investigations.

Figure 2 also shows impact-induced $\mathrm{H}_{2} \mathrm{O}$ loss for crystal-density serpentine [7] and for $20 \%$ porous serpentine [9], which approximate the range of densities of many carbonaceous chondrites [18]. These results bracket the data for Murchison, consistent with the observation that septechlorites are the major $\mathrm{H}_{2} \mathrm{O}$-bearing phase in Murchison. This also indicates that the results of devolatilization experiments on $\mathrm{Mg}$ end-member 
serpentine may be extrapolated to carbonaceous chondrites.

Laboratory shock pressures can be related to planetesimal impact velocities by assuming uniform, homogeneous accretion. For symmetric impact, the impact velocity required to generate a given shock pressure is twice the particle velocity of the shocked state. Minimum impact velocities onto a planetary surface are equal to the escape velocity of the planet. Thus, assuming constant density, the radius of the planet is a linear function of impact velocity

$$
r=V_{p}(8 \pi G \bar{\rho} / 3)^{-1 / 2}=2 u_{p}(8 \pi G \bar{\rho} / 3)^{-1 / 2}
$$

where $r$ is the planetary radius, $V_{p}$ is impact velocity, $G$ is the gravitational constant, $\bar{\rho}$ is the average density of the planet, and $u_{p}$ is the particle velocity. Figure 3 is a plot of shock-induced volatile loss versus fractional radius for Earth, Venus, and Mars using the parameterized devolatilization versus initial shock pressure results for Murchison presented here (solid line in Figure 2). For the Earth and Venus, impact-induced devolatilization of incident planetesimals would have begun by the time the planetary radii were about $12 \%$ of their present-day values, and complete devolatilization would have occurred when the planets reached about $27 \%$ of their present day radii. For Mars, incipient and complete devolatilization of incident planetesimals would occur at about 26 and $58 \%$, respectively, of its present day radius.

These results indicate that the initial volatile distribution will be extremely nonuniform in an accreting planet. In the absence of thermal effects, the net result of accretion as outlined above is a core with the volatile content and elemental composition of the incident material; a volatile depleted mantle will probably form in association with a metallic core, the core will sink into the center of the planet, and the volatiles depleted from the mantle will contribute to a volatile-rich veneer at the planetary surface. The distribution of volatiles between the interior and surface regions depends on planetary radius and mean density. Integrating with respect to mass along the curves in Figure 3 indicates that for the Earth, Venus, Mars, and a Moon-like planet, 99.4, 99.2, 93.2, and 
42.2 mass \%, respectively, of the incident volatiles end up at the planetary surface at the end of accretion. The possible existence of a planetary magma ocean in the later stages of accretion, whether caused by a runaway greenhouse effect due to the accumulating protoatmosphere $[4]$ or by retention of heat deposited during impact [20], does not alter the conclusion that a volatile-containing core surrounded by volatile-depleted region exists early in planetary accretion. The existence of heat generated by core formation and radioactive decay, of course, profoundly affects planetary differentiation.

\section{Conclusions}

Impact-induced $\mathrm{H}_{2} \mathrm{O}$ loss and total volatile loss from a carbonaceous chondrite have the same dependence on shock pressure. Thus, there is no enrichment or depletion of $\mathrm{H}_{2} \mathrm{O}$ relative to other volatile species in gases released from a carbonaceous chondrite upon impact. The actual impact pressure dependence is bracketed by results for crystal density serpentine and $20 \%$ porous serpentine. For the Earth, incipient devolatilization of accreting planetesimals occurred when the planet reached $12 \%$ of its present day radius, and complete devolatilization occurred at $27 \%$ of its present day radius. Therefore, impact-induced devolatilization of accreting planetesimals played a major role in altering the distribution of volatiles during accretion. Prior to metallic core formation and internal differentiation, 99.4 mass \% of the incident volatiles would be found in the near surface environment (including a possible surficial magma ocean), the remainder residing in the core region, with a volatile depleted 'mantle' between them.

Acknowledgments. Supported under NASA Grant NGL-05-002-105. We are grateful to Professor Carleton Moore and the Center for Meteorite Studies, Arizona State University for samples. We appreciate the use of laboratory facilities operated by George Rossman and E. M. Stolper as well as helpful comments on the manuscript proferred by William Anderson. Division of Geological and Planetary Sciences Contribution no. 4293. 


\section{References}

[1] G. Arrhenius, B.R. De and H. Alfven, Origin of the ocean, in: The Sea, E. D. Goldberg, ed., pp. 839-861, Wiley, New York, 1974.

[2] A. Benlow and A.J. Meadows, The formation of the atmospheres of the terrestrial planets by impact, Astrophys. Space Sci. 46, 293-300, 1977.

[3] M.A. Lange and T.J. Ahrens, The evolution of an impact-generated atmosphere, Icarus $51,96-120,1982$.

[4] Y. Abe and T. Matsui, The formation of an impact-generated $\mathrm{H}_{2} \mathrm{O}$ atmosphere and its implications for the early thermal history of the Earth, Proc. Lunar Sci. Conf. 15th, Part 2, J. Geophys. Res., 90, C545-559, 1985.

[5] M.A. Lange and T.J. Ahrens, Impact induced dehydration of serpentine and the evolution of planetary atmospheres, Proc. Lunar Planet. Sci. Conf. 13th, Part I, J. Geophys. Res. 87, A451-A456, 1982.

[6] M.A. Lange and T.J. Ahrens, Shock-induced $\mathrm{CO}_{2}$-production from carbonates and a proto- $\mathrm{CO}_{2}$ atmosphere on the earth, preprint in preparation, 1985.

[7] M.A. Lange, P. Lambert and T.J. Ahrens, Shock effects on hydrous minerals and implications for carbonaceous meteorites, Geochim. Cosmochim. Acta, 49, 1715$1726,1985$.

[8] D.J. Barber, Matrix phyllosilicates and associated minerals in C2M carbonaceous chondrites, Geochim. Cosmochim. Acta, 45, 945-970, 1981.

[9] J.A. Tyburczy and T.J. Ahrens, in preparation, 1986.

[10] M.H. Rice, R.G. McQueen and J.M. Walsh, Compression of solids by strong shock waves, Solid State Physics, 6, 1-63, 1985.

[11] S.P. Marsh (ed.), LASL Shock Hugoniot Data, Univ. of Calif. Press, Berkeley, pp. $327,1980$.

[12] D. Stöfler, Deformation and transformation of rock-forming minerals by natural and experimental shock processes, Fortschr. Miner., 49, 50-113, 1972.

[13] T.J. Ahrens and J.D. O'Keefe, Shock melting and vaporization of lunar rocks and minerals, Moon, 4, 214-249, 1972. 
[14] J.A. Tyburczy and T.J. Ahrens, Dynamic compression and volatile release of carbonates, J. Geophys. Res., in press, 1986.

[15] M.B. Boslough, R.J. Weldon and T.J. Ahrens, Impact-induced water loss from serpentine, nontronite, and kernite, Proc. Lunar Sci. Conf. 11th, 2145-2158, 1980.

[16] M.A. Lange and T.J. Ahrens, Shock-induced $\mathrm{CO}_{2}$-production from carbonates and a proto- $\mathrm{CO}_{2}$ atmosphere on the Earth, Lunar Planet. Sci. XIV, 419-420, 1983.

[17] J.A. Tyburczy and T.J. Ahrens, Partial pressure of $\mathrm{CO}_{2}$ and impact-induced devolatilization of carbonates: Implications for planetary accretion, Lunar Planet. Sci. XVI, 874-875, 1985.

[18] Y. Yomogida and T. Matsui, Physical properties of ordinary chondrites, J. Geophys. Res., 88, 9513-9533, 1983.

[19] L.H. Fuchs, E. Olsen and K.J. Jensen, Mineralogy, crystal chemistry and composition of the Murchison (C2) meteorite, Smithsonian Contrib. Earth Sci., 10, 1-39, 1973.

[20] G.F. Davis, Heat deposition and retention in a solid planet growing by impacts, Icarus, 63, 45-68, 1985. 


\section{TABLE 1}

Volatile-containing minerals in Murchison [19]

Water

Serpentine - $(\mathrm{Mg}, \mathrm{Fe})_{3} \mathrm{Si}_{2} \mathrm{O}_{5}(\mathrm{OH})_{4}$ (Septechlorites)

Montmorillonite -

$(\mathrm{Na}, 1 / 2 \mathrm{Ca})_{.33}(\mathrm{Al}, \mathrm{Mg})_{2} \mathrm{Sl}_{4} \mathrm{O}_{10}(\mathrm{OH})_{2} \cdot \mathrm{nH}_{2} \mathrm{O}$

Brucite - $\mathrm{Mg}(\mathrm{OH})_{2}$

Limonite $-\mathrm{Fe}_{2} \mathrm{O}_{3} \cdot \mathrm{nH}_{2} \mathrm{O}$

Sepiolite $-\mathrm{Mg}_{2} \mathrm{Si}_{3} \mathrm{O}_{8} \cdot 2 \mathrm{H}_{2} \mathrm{O}$

$\mathrm{Mg}$-Sulfate - $\mathrm{MgSO}_{4} \cdot \mathrm{nH}_{2} \mathrm{O}$

Gypsum - $\mathrm{CaSO}_{4} \cdot 2 \mathrm{H}_{2} \mathrm{O}$

Bloedite - $\mathrm{Na}_{2} \mathrm{Mg}\left(\mathrm{SO}_{4}\right)_{2} \cdot 2 \mathrm{H}_{2} \mathrm{O}$

Whewellite $-\mathrm{CaC}_{2} \mathrm{O}_{4} \cdot \mathrm{H}_{2} \mathrm{O}$
Carbon

Hydrocarbons*

$(\mathrm{H} / \mathrm{C} \sim 1)$

Graphite - C

Calcite $-\mathrm{CaCO}_{3}$

Whewellite $-\mathrm{CaC}_{2} \mathrm{O}_{4} \cdot \mathrm{H}_{2} \mathrm{O}$ $\underline{\text { Sulfur }}$

Disseminated S*

Troilite - FeS

Pentlandite -

$(\mathrm{Fe}, \mathrm{Ni})_{8} \mathrm{~S}_{8}$

**FeSO phase

Gypsum - $\mathrm{CaSO}_{4} \cdot 2 \mathrm{H}_{2} \mathrm{O}$

* Major volatile bearing phase.

**Poorly characterized, unidentified $\mathrm{Fe}, \mathrm{S}, \mathrm{O}$ containing phase. 
Table 2. Experimental Results

\begin{tabular}{|c|c|c|c|c|c|c|}
\hline $\begin{array}{l}\text { Shot } \\
\text { number }\end{array}$ & $\begin{array}{c}\text { Sample } \\
\text { mass, } \\
\text { mg }\end{array}$ & $\begin{array}{l}\text { Projectile } \\
\text { Velocity } \\
\text { km/s }\end{array}$ & $\begin{array}{c}\text { Initial } \\
\text { Shock } \\
\text { Pressure, } \\
\text { GPa }\end{array}$ & $\begin{array}{c}\text { Peak } \\
\text { Shock } \\
\text { Pressure, } \\
\text { GPa }\end{array}$ & $\begin{array}{c}\text { Total } \\
\text { Volatile } \\
\text { Loss, } \\
20^{\circ}-1200^{\circ} \mathrm{C}, \\
\% \text { of } \\
\text { initial }\end{array}$ & $\begin{array}{c}\mathrm{H}_{2} \mathrm{O} \text { Loss, } \\
20^{\circ} \mathrm{C}-1200^{\circ} \mathrm{C} \text {, } \\
\% \text { of } \\
\text { initial }\end{array}$ \\
\hline 799 & 19.6 & $\begin{array}{r}1.08 \\
\pm 0.03\end{array}$ & $\begin{array}{r}13.3 \\
\pm 0.4\end{array}$ & $\begin{array}{r}22.9 \\
\pm 0.7\end{array}$ & - & $\begin{array}{r}14.4 \\
\pm 3.5\end{array}$ \\
\hline 803 & 19.0 & $\begin{array}{r}1.21 \\
\pm 0.02\end{array}$ & $\begin{array}{r}15.1 \\
\pm 0.3\end{array}$ & $\begin{array}{r}26.2 \\
\pm 0.5\end{array}$ & - & $\begin{array}{r}40.0 \\
\pm 5.0\end{array}$ \\
\hline 785 & 19.3 & $\begin{array}{r}1.40 \\
\pm 0.10\end{array}$ & $\begin{array}{r}17.3 \\
\pm 1.4\end{array}$ & $\begin{array}{r}31.1 \\
\pm 2.7\end{array}$ & $\begin{array}{r}40.0 \\
\pm 5.0\end{array}$ & - \\
\hline 835 & 17.6 & $\begin{array}{r}1.67 \\
\pm 0.01\end{array}$ & $\begin{array}{r}21.5 \\
\pm 0.1\end{array}$ & $\begin{array}{r}38.4 \\
\pm 0.3\end{array}$ & $\begin{array}{r}87.4 \\
\pm 2.6\end{array}$ & $\begin{array}{r}89.5 \\
\pm 6.7\end{array}$ \\
\hline 825 & 39.5 & $\begin{array}{r}1.84 \\
\pm 0.01\end{array}$ & $\begin{array}{r}24.0 \\
\pm 0.2\end{array}$ & $\begin{array}{r}43.2 \\
\pm 0.5\end{array}$ & $\begin{array}{r}81.3 \\
\pm 3.8\end{array}$ & \\
\hline 781 & 19.4 & $\begin{array}{r}2.06 \\
\pm 0.10\end{array}$ & $\begin{array}{r}27.3 \\
\pm 1.5\end{array}$ & $\begin{array}{r}49.7 \\
\pm 3.1\end{array}$ & $\begin{array}{r}48.0 \\
\pm 10.0\end{array}$ & $\begin{array}{r}89.0 \\
\pm 5.0\end{array}$ \\
\hline
\end{tabular}




\section{Figure Captions}

Figure 1. Representative thermogravimetric analysis (TGA) curves for unshocked and shocked Murchison. Mass loss increases downward. For the shocked samples, the impact-induced mass loss is represented by the difference between the final $\left(1200^{\circ} \mathrm{C}\right)$ value and $100 \%$. $100 \%$ mass loss refers to the mass loss between 200 and $1200^{\circ} \mathrm{C}$ for unshocked Murchison.

Figure 2. Shock-induced mass loss as a function of initial shock pressure for Murchison. Squares represent $\mathrm{H}_{2} \mathrm{O}$ loss; circles, total volatile loss. Solid line is a polynomial fit to the data. Dashed lines are fits to data on impact-induced dehydration of $20 \%$ porous serpentine [9] and crystal-density serpentine [7].

Figure 3. Impact-induced devolatilization of Murchison as a function of fractional planetary radius and mass for the Earth, Venus, Mars, respectively. 


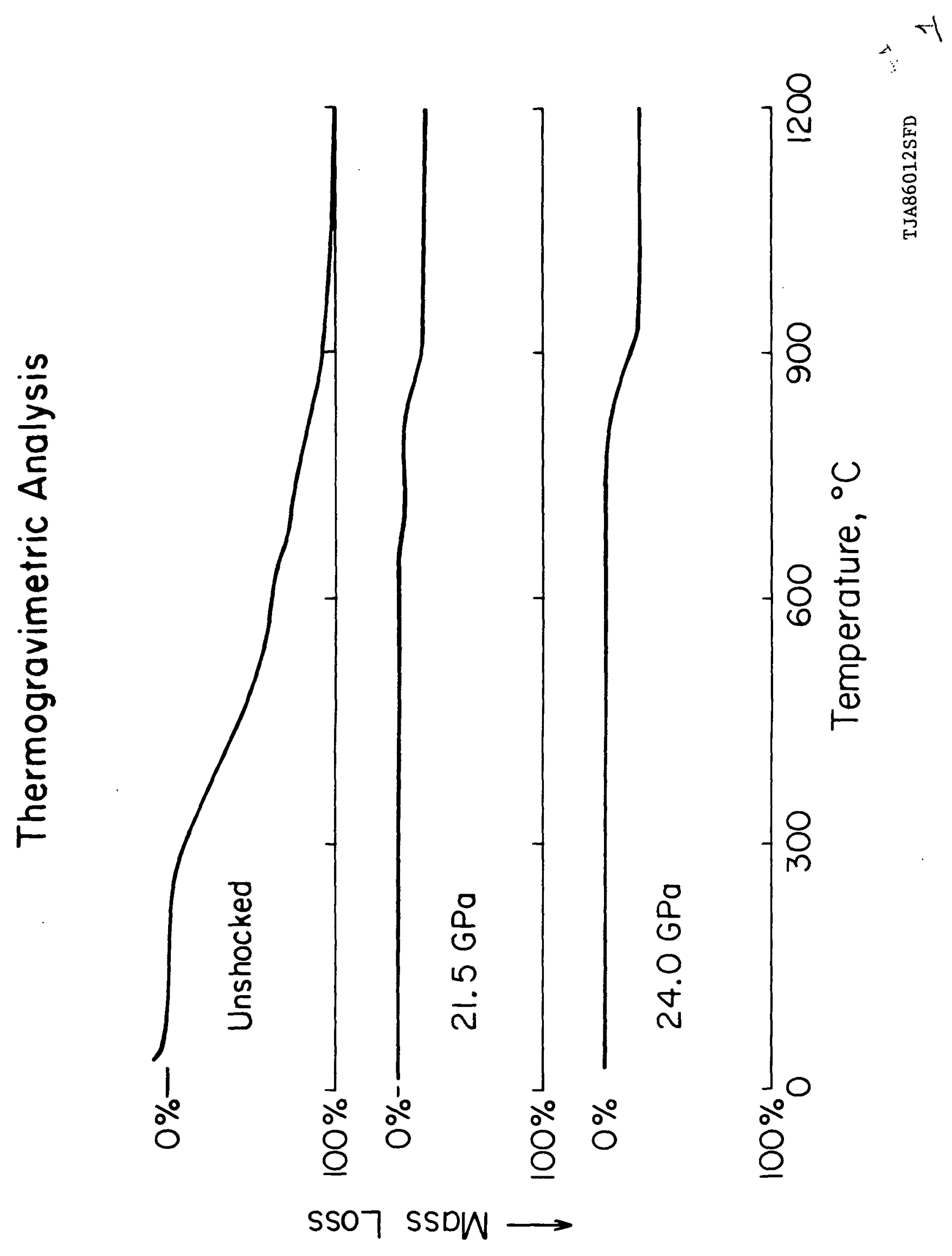




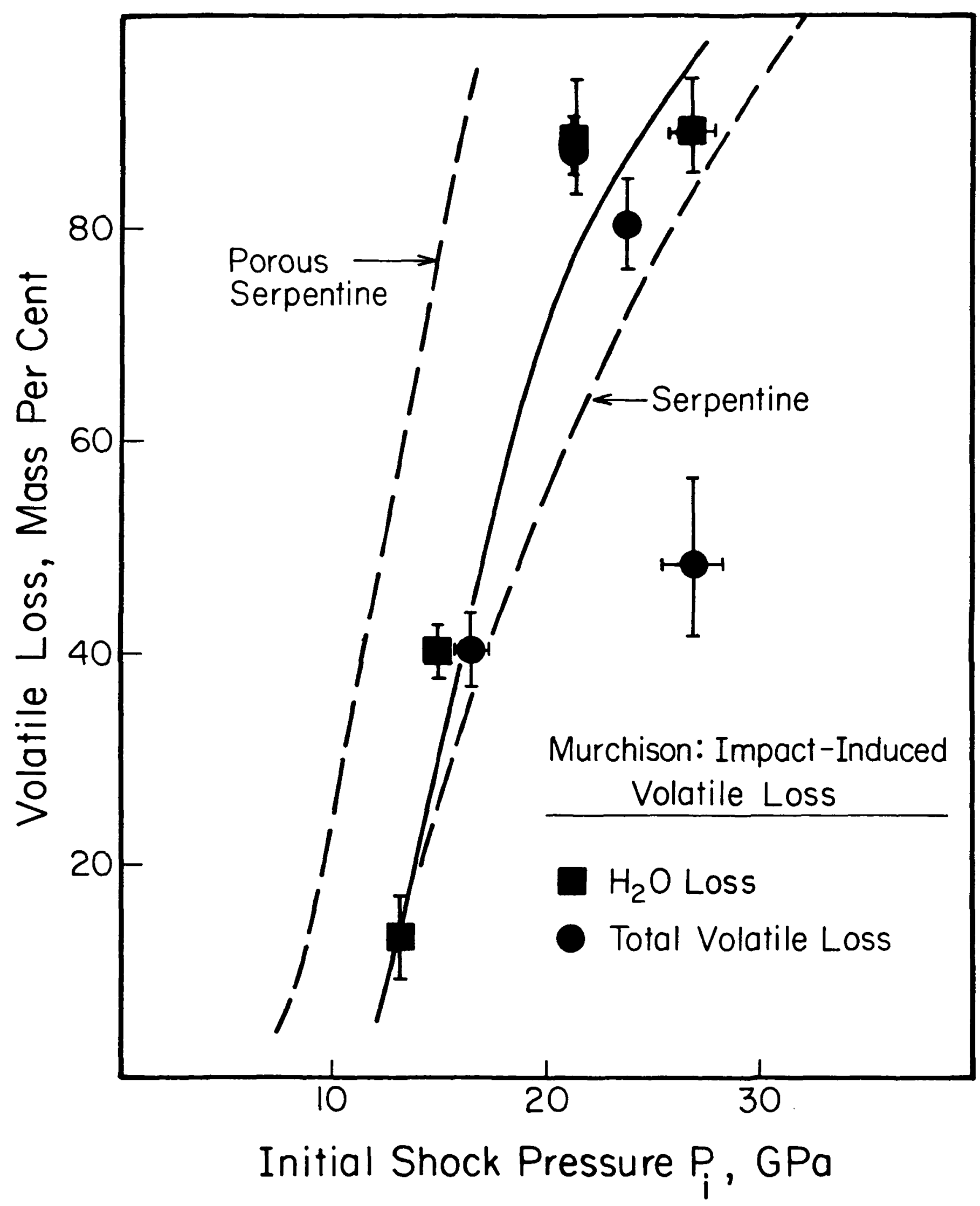




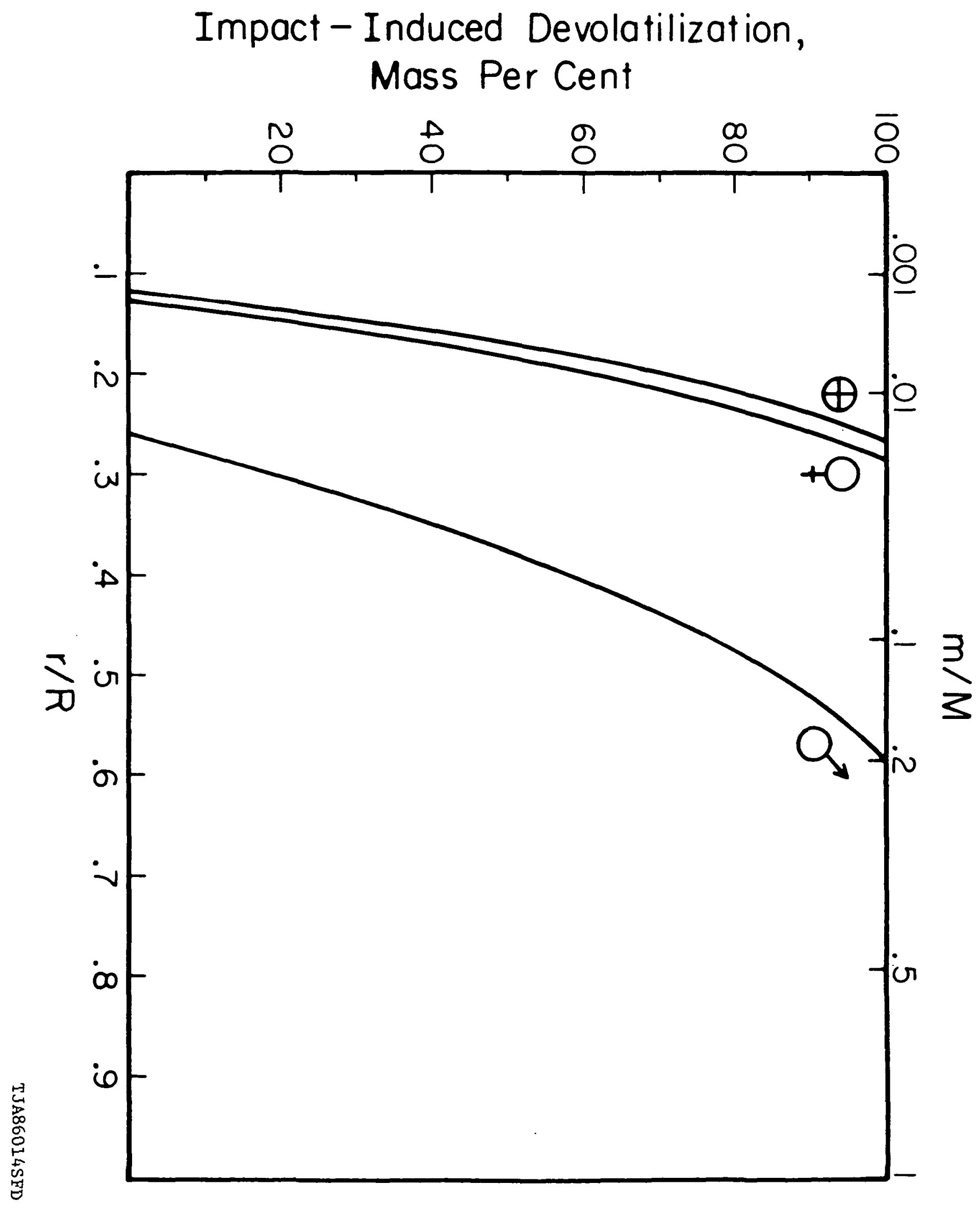

